\title{
Sensitive Spectrophotometric Determination of Deltamethrin Insecticide in its Formulation and Environmental Samples
}

\author{
Alaa S. Amin \\ Chemistry Department, Faculty of Science, \\ Benha University, Benha, Egypt. \\ Mohammed S. Salama, \\ Plant protection research institute, agricultural \\ research center, Ismailia, Egypt.
}

\author{
Sayed M.N. Moalla, Amani Ali \\ Chemistry Department, Faculty of Science, Port \\ Said University, Port Said, Egypt.
}

Ayman A. Gouda,

Chemistry Department, Faculty of Science, Zagazig University, Zagazig, 44519, Egypt. Faculty of Public Health and Informatics, Umm AL-Qura University, Makkah, Saudi Arabia.

\begin{abstract}
Three sensitive spectrophotometric methods were developed for the determination of deltamethrin as synthetic pyrethroid in its formulations and environmental samples. The proposed methods were based on the hydrolysis of deltamethrin with ethanolic $\mathrm{KOH}$ to form 3-phenoxy benzaldehyde which condensation with anthranilic acid (Method A), 4-aminoantipyrine (method B) and 2-chlorophenyl hydrazine (method C) to form color product having $\lambda_{\max }$ at 480, 495 and $552 \mathrm{~nm}$, for methods $A, B$ and $C$, respectively. The color derivatives were stable for 3, 5 and 6 days for methods $A, B$ and $C$, respectively. The Beer's law was obeyed over the

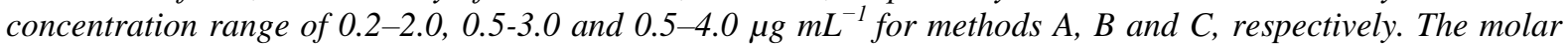
absorptivity and Sandell's sensitivity, detection and quantification limits were calculated. The proposed methods have been successfully applied for the determination of deltamethrin in its formulations and environmental samples.
\end{abstract}

Keywords:Deltamethrin, Anthranilic acid, 4- aminoantipyrine, 2- chlorophenyl hydrazine, Spectrophotometry, Formulations, Environmental samples.

\section{INTRODUCTION}

Pyrethroid insecticides are derived from natural compounds (the pyrethrins), isolated from Chrysanthemum genus of plants. Pyrethroid pesticides, widely used on crops like cotton, fruits and lettuce, appear to be a significant source of sediment toxicity in urban and agriculturally dominated streams. Pyrethroids act as neurotoxins and target the central nervous system of insects [1]. Pyrethroid pesticides are toxic to man and animals, carcinogenic to human and exert genotoxic, mutagenic and embryotoxic effects [2]. The use of pyrethroid insecticides is increasing for agriculture, commercial pest control and residential consumer use. These insecticides are intensively used for a variety of crops, its residue enters into inland water sources from the fields where it has been applied and contaminates the adjacent streams, ponds, lakes, wells, etc. The insecticides are highly stable under acidic conditions, though unstable at $\mathrm{pH}$ 8.0.

Synthetic pyrethroids containing nitrile group such as, deltamethrin: $(S)$-cyano-3-phenoxybenzyl $(1 R$, 3R)-3-(2,2-dibromovinyl)-2,2-dimethyl cyclopropane carboxylate (Scheme 1) is synthetic pyrethroid that has been used for the management of a variety of insect pests [3]. Deltamethrin kills insects on contact and through digestion. It works by paralyzing the insect's nervous system and therefore giving a quick knock down effect. It is used commonly to control eaterpillars on apples, pears and hops and for the control of aplids, mearly bugs, scale insects and whiteflies on glass house cucumbers, tomatoes and ornamentals.

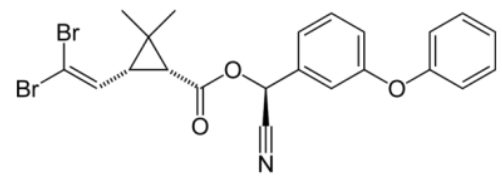

Scheme1. The chemical structure of deltarmethrin 
Because of its significance, several analytical methods have been developed for the determination of synthetic pyrethroid deltamethrin based on the use of chromatographic techniques which include high performance liquid chromatography (HPLC) [4-8], Liquid chromotography-mass spectroscopy (LCMS, [9], gas chromatography-electron (GC-ECD) [10, 11] and solid phase extraction [12] and electrochemical methods [13-16]. These techniques required large number of solvents for the extractions and also some limitations in terms of high cost of instruments used in routine analysis and matrix effects.

Spectrophotometric method is still one of the important techniques for the determination of pesticides because it is less expensive and easy to use. The availability of spectrophotometric apparatus and the simplicity of analytical procedures made the technique very attractive for a wide range of application. Various spectrophotometric methods have also been reported for determination of deltamethrin [17, 18].

The aim of the present work is to develop facile, rapid, low cost, accurate and sensitive spectrophotometric method for the determination of deltamethrin based on the condensation of the hydrolyzed aldehyde group with anthranilic acid, 4-aminoantipyrine and 2-chlorophenyl hydrazine. The developed methods have been successfully employed for the determination of deltamethrin in its formulations, environmental samples (water, grain, vegetables and fruits).

\section{EXPERIMENTAL}

\subsection{Apparatus}

A Varian UV-Vis spectrophotometer model (Carry 100) with matched quartz cells was used for all spectral measurements. Hanna pH-meter instrument equipped with a combined glass-calomel electrode (Portogal) (HI: 9321) was used for checking the $\mathrm{pH}$ of solutions.

\subsection{Reagents}

All reagents used were of Anala $\mathrm{R}$ grade or of the best available quality. Double distilled demineralized water was used throughout. Technical grade samples of detamethrin were obtained from Bayer India Limited, India.

\subsubsection{Standard solution of deltamethrin $\left(100 \mu \mathrm{g} \mathrm{mL^{-1 }}\right)$}

To $10 \mathrm{mg}$ of deltamethrin were dissolved in $25 \mathrm{~mL}$ of methanol, $2.0 \mathrm{~mL}$ of $2.0 \%$ (w/v) sodium hydroxide was added and after 5.0 min the solution was made up to volume in a $100 \mathrm{~mL}$ standard flask with methanol. Working standard solution containing $100 \mu \mathrm{g} \mathrm{mL}-1$ was prepared by appropriate dilution of the stock standard solution with methanol. Deltamethrin stock solution was preserved at 4 ${ }^{\circ} \mathrm{C}$ in a refrigerator and desired concentrations were prepared freshly.

\subsubsection{Deltamethrin formulations}

DeltaGard SC (50 g/L), Bayer Environmental Science Canada. Deltamethrin 5.0\%EC Bessen Chemical CO., LTD., China.

A $0.3 \%(\mathrm{w} / \mathrm{v})$ of 4-aminoantipyrine, anthranilic acid and 2-chlorophenyl hydrazine were prepared by dissolving $0.3 \mathrm{~g}$ in $100 \mathrm{~mL}$ methanol.

A $2.0 \%(\mathrm{w} / \mathrm{v})$ methanolic $\mathrm{KOH}$ and concentrated and $0.1 \mathrm{~N} \mathrm{HCl}$ solutions were used for the experiments.

\subsection{General procedures}

A aliquot $0.5-20 \mu \mathrm{g} \mathrm{mL}-1$ of standard deltamethrin solution were taken into a clean dry $50 \mathrm{~mL}$ volumetric flasks. Five milliliters of $2.0 \%$ (w/v) methanolic potassium hydroxide solution was added to deltamethrin solution and allowed to stand for $5.0 \mathrm{~min}$ for complete hydrolysis, heated $40-45^{\circ} \mathrm{C}$ for $30 \mathrm{~min}$ and neutralised with $0.1 \mathrm{~N} \mathrm{HCl}, 2.0 \mathrm{~mL}$ of $0.2 \%$ (w/v) 4 -aminoantipyrine was added followed by one drop of concentrated $\mathrm{HCl}$ and heated to $35-50{ }^{\circ} \mathrm{C}$ for $30 \mathrm{~min}$ for color development and completed to the mark with bidistilled water. The same procedure was adopted for of $0.3 \%(\mathrm{w} / \mathrm{v})$ of anthranilic acid and 4-chlorophenyl hydrazine. The absorbance of the color derivatives were measured at $\lambda \max 480,495$ and $552 \mathrm{~nm}$, for methods A, B and C, respectively against reagent blank. 


\subsection{Determination of deltamethrin in its formulations}

Weight or take a volume of deltamethrin formulations, equivalent to $50 \mathrm{mg}$ of deltamethrin and placed in a porcelain dish, then $20 \mathrm{~mL}$ of methanol was added. This mixture centrifuged for $5.0 \mathrm{~min}$ and heated on a hot water bath then evaporated the solvent. The washing of the residue with $10 \mathrm{~mL}$ of methanol three times, and the resulting solution was diluted to $50 \mathrm{~mL}$ with methanol in a calibrated flask. The deltamethrin was determined by the aforesaid procedures.

\subsection{Determination of deltamethrin in water samples}

A volume of $100 \mathrm{~mL}$ runoff water (tap and river water) were collected in PTHE bottles from different agriculture fields where deltamethrin had been sprayed. The samples were filtered and $1.0 \mathrm{~mL}$ of $5.0 \%$ EDTA was added to each of them to remove various metal ions. Each sample was extracted with chloroform $(2.0 \times 100 \mathrm{~mL})$. The extracts were combined and washed with $20 \mathrm{~mL}$ of $0.1 \mathrm{M}$ $\mathrm{K} 2 \mathrm{CO} 3$ solution to break any emulsions. The chloroform extracts were dried over anhydrous sodium sulfate in a filter funnel and the filtrate was collected in a $250 \mathrm{~mL}$ calibrated flask. The filter funnel was washed with $20 \mathrm{~mL}$ of chloroform and the volume of the filtrate was made up to the mark, known aliquots of chloroform extracts were taken and evaporated on a water bath at about $50^{\circ} \mathrm{C}$. The residue was dissolved in $10 \mathrm{~mL}$ methanol. The solution was then transferred into a separating funnel with 25 $\mathrm{mL}$ of water [19] and to it sodium hydroxide was added and analyzed as described above.

\subsection{Determination of deltamethrin in grain samples (rice and wheat)}

In order to check the validity of the proposed methods, different samples of grains (rice and wheat) $(25 \mathrm{~g})$ were collected from the fields where deltamethrin had been sprayed. The samples were weighed, macerated and blended in a mixer. Then $1.0 \mathrm{~mL}$ of $5.0 \%$ EDTA was added to the blended sample and was extracted using $25 \mathrm{~mL}$ chloroform. After extraction, the samples were spiked with different concentrations of deltamethrin in $10 \mathrm{~mL}$ of methanol. the spiked samples were blended for a further $2.0 \mathrm{~min}$. The chloroform solution was then decanted into a $250 \mathrm{~mL}$ calibrated flask through Whatman No. 1 filter paper. Blending and decanting was repeated twice with $10 \mathrm{~mL}$ portions of chloroform. The extracts were combined and diluted to the mark. The chloroform extract was evaporated off, under reduced pressure, using a water bath at about $50{ }^{\circ} \mathrm{C}$ [19]. The residue was dissolved in $10 \mathrm{~mL}$ methanol and the color developed as described before.

\subsection{Determination of deltamethrin in vegetables and fruits}

Various samples of vegetables (tomatoes and cauliflower) and fruits (apples), each of $25 \mathrm{~g}$, were collected from agricultural fields, where deltamethrin had been sprayed as an insecticide. The samples were macerated with two $20 \mathrm{~mL}$ portions of ethanol-distilled water $(1: 1)$, filtered through a thin cotton cloth and the filtrate was centrifuged. The filtrate was quantitatively transferred into a $25 \mathrm{~mL}$ volumetric flask and made up to the mark with $50 \%$ ethanol. Aliquots of supernatant were taken in a $25 \mathrm{~mL}$ graduated cylinder and then analyzed. Filtrate from foliages were passed through a silica gel column filled with $5.0 \mathrm{mg}$ silica gel, which was found to be sufficient for removal of chlorophyll and other interfering materials present in the extracted sample [19]. The column was washed with $10 \mathrm{~mL}$ of $50 \%$ ethanol, washings were collected in a $25 \mathrm{~mL}$ volumetric flask and analyzed as recommended by the above procedures.

\section{RESUlts AND DiscusSiON}

\subsection{Spectral characteristics}

The method involved alcoholic alkaline hydrolysis of deltamethrin to form 3-phenoxy benzaldehyde followed by condensation with 4-aminoantipyrine, anthranilic acid and 2-chlorophenyl hydrazine. The hydrolyzed deltamethrin forms red, orange red and pink color derivatives having $\lambda$ max at 480, 495 and $552 \mathrm{~nm}$, for methods A, B and C, respectively. The corresponding reagent blanks have practically negligible absorbance at these wavelengths as shown in Figure 1. The formation of color derivatives of deltamethrin with the reagents was shown in Scheme 2. 


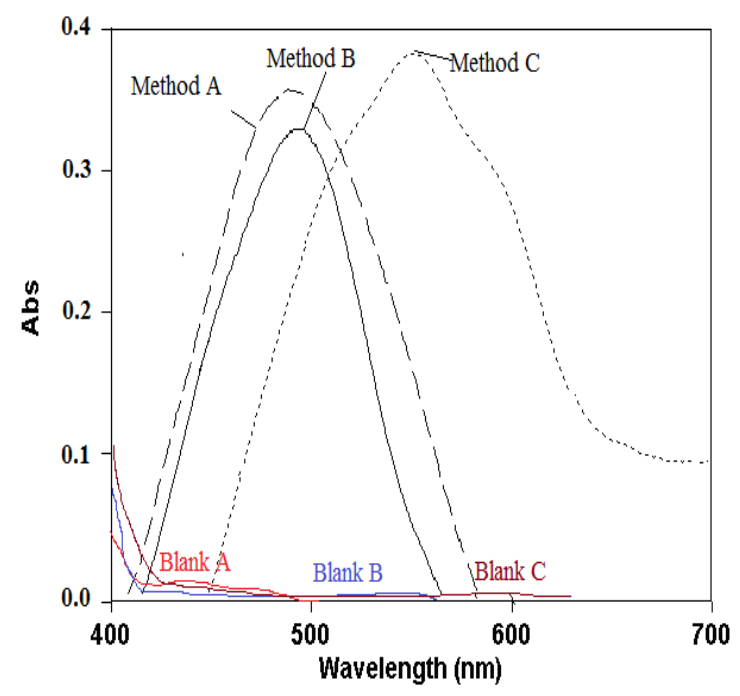

Figure1. Absorption spectra of deltarmethrin with the studied reagents.
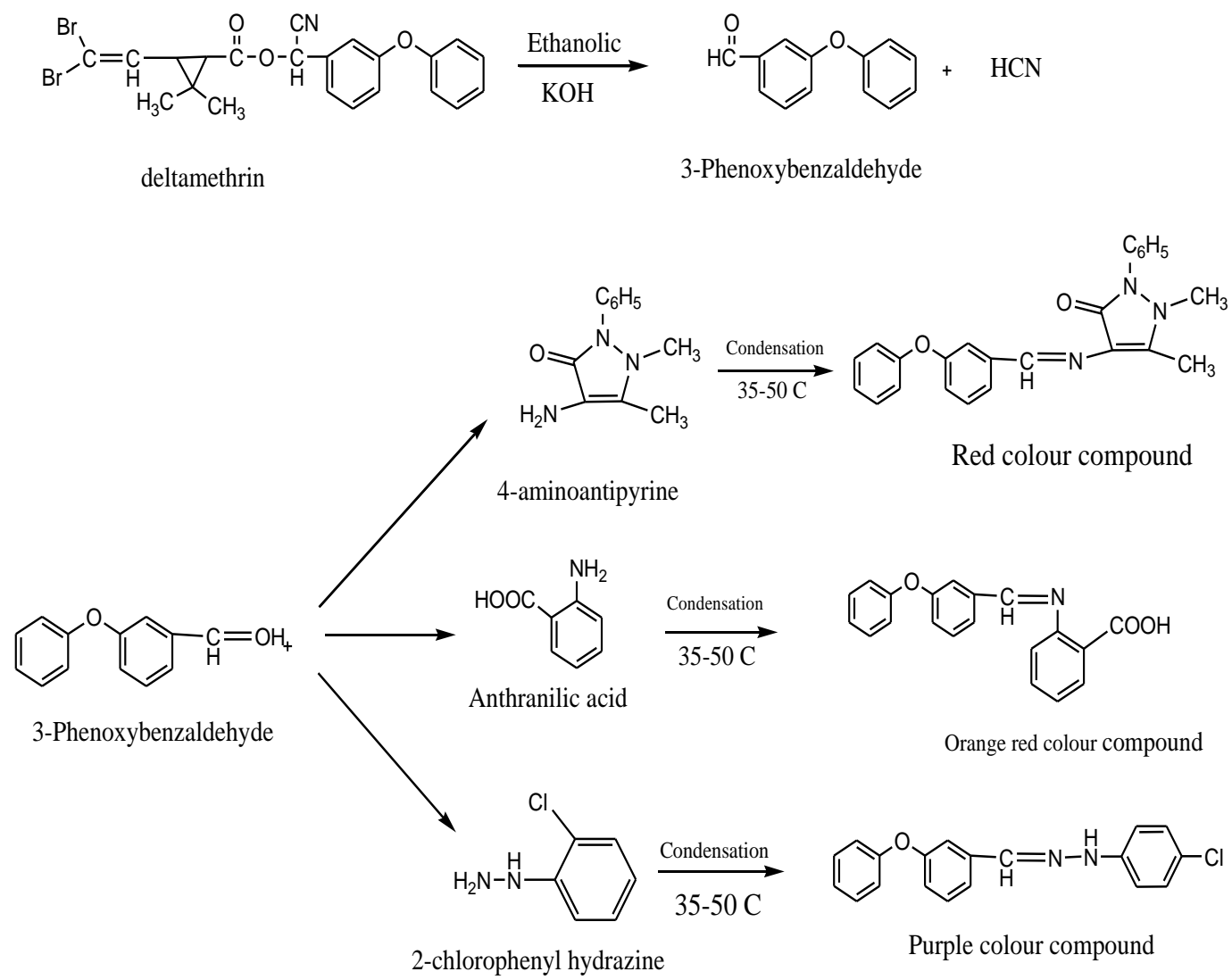

Scheme2. Color product of the deltarmethrin with 4-aminoantipyrine, anthranilic acid and 2-chlorophenyl hydrazine.

\subsection{Optimization of conditions}

Hydrolysis of deltamethrin to 3-phenoxy benzaldehyde was studied at different temperatures and alkalinity. It was observed that alkaline conditions were required for the hydrolysis. Maximum hydrolysis was observed with $2.0 \%(\mathrm{w} / \mathrm{v})$ potassium hydroxide at a temperature range of $40-45^{\circ} \mathrm{C}$ for $30 \mathrm{~min}$ [20] as it gave maximum absorbance values, good stability and quantitative results.

Various concentrations and volume ranges of deltamethrin were studied. However, the following optimum concentrations and volume ranges were needed for color development. In the proposed methods, it was found that $5.0 \mathrm{~mL}$ of $2.0 \%$ (w/v) methanolic $\mathrm{KOH}$ with $2.0 \mathrm{~mL}$ of $0.3 \%$ (w/v) of 4aminoantipyrine, anthranilic acid or 2-chlorophenyl hydrazine (Figure 2) at $\mathrm{pH}$ 6.5-7.5 (Figure 3) was sufficient for complete colour reaction to achieve the maximum color intensity. 
Sensitive Spectrophotometric Determination of Deltamethrin Insecticide in its Formulation and Environmental Samples

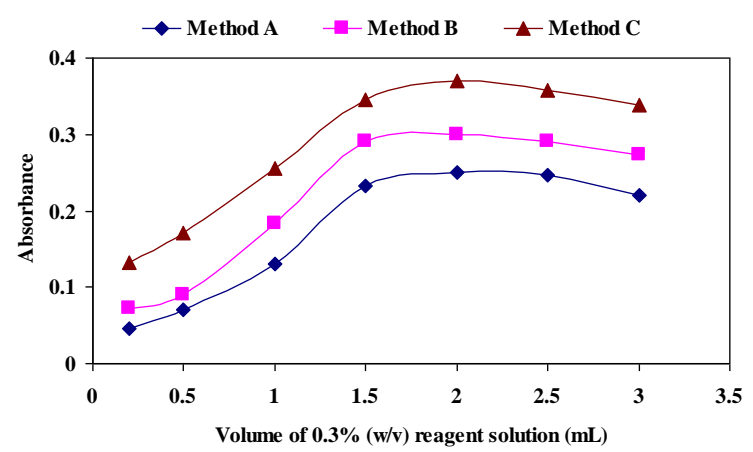

Figure2. Effect of volume of $0.3 \%(w / v)$ reagent on the intensity of the coloured product.

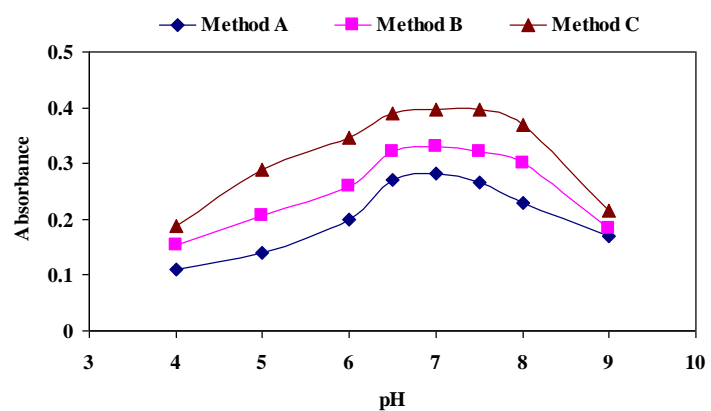

Figure 3. Effect of pH on deltarmethrin with 4-aminoantipyrine, anthranilic acid and 2-chlorophenyl hydrazine reagents.

\subsection{Effect of foreign species}

To assess the validity of the proposed method, the interference from foreign ions commonly found with deltamethrin as synthetic pyrethroide were studied by adding known amounts of diverse ions and foreign species and pesticides to standard solution contained $5.0 \mu \mathrm{g}$ of deltamethrin in $10 \mathrm{~mL}$ of final solution prior to hydrolysis and the solution was analysed by the proposed methods. The methods were found to be free from interferences of most of the foreign species and pesticides (Table 1).

Table1. Effect of foreign species for determination of deltamethrin $(5.0 \mu \mathrm{g}$ per $10 \mathrm{~mL})$

\begin{tabular}{|l|l|l|l|}
\hline Foreign species & $\begin{array}{l}\text { Tolerance limit } \\
\boldsymbol{\mu} \mathbf{g} \mathbf{~ m L}^{-1}\end{array}$ & Foreign species & $\begin{array}{l}\text { Tolerance limit } \\
\boldsymbol{\mu} \mathbf{~ m L}^{\mathbf{1}}\end{array}$ \\
\hline Benzene & 3000 & Atrazine & 50 \\
\hline Phenol, Ethanol & 2000 & $\mathrm{Al}^{3+}, \mathrm{Mg}^{2+}, \mathrm{Ca}^{2+}$ & 1000 \\
\hline Benzaldehyde & 1000 & $\mathrm{Fe}^{3+}, \mathrm{Fe}^{2+}$ & 600 \\
\hline Toluene, Xylene & 900 & $\mathrm{Ni}^{2+}, \mathrm{Pb}^{2+}, \mathrm{Ca}^{2+}$ & 500 \\
\hline Aniline, Formaldehyde & 500 & $\mathrm{Br}^{-}, \mathrm{CO}_{3}{ }^{2-}, \mathrm{Cl}^{-}$ & 400 \\
\hline Parathion, Malathion, Cresol & 100 & $\mathrm{NO}_{2}^{-}$ & 100 \\
\hline
\end{tabular}

${ }^{a}$ The amount causing an error of $\pm 2.0 \%$ in absorbance value.

\subsection{Analytical data}

By using the above procedure, linear regression equations were obtained. The regression plots showed that there was a linear dependence of the analytical response in the proposed methods to the concentration of deltamethrin over the ranges cited in Table 2. Linear regression analysis of the data gave the following equations, For method $\mathrm{A}, \mathrm{A}=0.1512 \mathrm{C}+0.0027, \mathrm{r}=0.9992$, for method $\mathrm{B}, \mathrm{A}=$ $0.1156 \mathrm{C}-0.0019, \mathrm{r}=0.9993$ and for method $\mathrm{C}, \mathrm{A}=0.0969 \mathrm{C}-0.0003, \mathrm{r}=0.9996$. Where $\mathrm{A}$ is the absorbance, $\mathrm{C}$ is the concentration of deltamethrin ( $\mu \mathrm{g} \mathrm{mL}-1)$, and $\mathrm{r}$ is the correlation coefficient. The Beer's law limits, molar absorptivity, Sandell's sensitivity, slope, intercept, correlation coefficients and optimum concentration ranges by photometric determinations are summarized in Table 2 . The limits of detection (LOD) was determined by establishing the minimum level at which the analyte can be reliably detected, and the results are also summarized in Table 2. LOQ and LOD were calculated according to the following equations [21]: 
Alaa S. Amin et al.

$\mathrm{LOQ}=10 \mathrm{~s} / \mathrm{b}$

$\mathrm{LOD}=3.3 \mathrm{~s} / \mathrm{b}$

Where $\mathrm{s}$ is the standard deviation of the blank with respect to water, $\mathrm{b}$ : is the slope of the calibration curve. The proposed methods were evaluated for the accuracy as percent relative error (\% RE) and the precision as percent relative standard deviation (\% RSD) (Tables 2).

The performance of the proposed method was compared statistically in terms of student's $t$ test and the variance ratio of F-test and shown in Table 2. These tests show no significant difference between the proposed method and reported method [18], indicating that the proposed method is accurate and precise.

Table2. Analytical parameters for the spectrophotometric determination of deltamethrin using the proposed methods.

\begin{tabular}{|c|c|c|c|}
\hline Parameters & Method A & Method B & Method C \\
\hline$\lambda_{\max }(\mathrm{nm})$ & 480 & 495 & 552 \\
\hline Concentration range $\left(\mu \mathrm{g} \mathrm{mL}^{-1}\right)$ & $0.2-2.0$ & $0.5-3.0$ & $0.5-4.0$ \\
\hline Molar absorptivity $\left(1 \mathrm{~mol}^{-1} \mathrm{~cm}^{-1}\right) \times 10^{5}$ & 0.7948 & 0.5763 & 0.4761 \\
\hline Sandell's sensitivity $\left(\mathrm{ng} \mathrm{cm}^{-2}\right)$ & 6.36 & 8.77 & 10.61 \\
\hline \multicolumn{4}{|l|}{ Regression equation $^{a}$} \\
\hline Slope $(b)$ & 0.1512 & 0.1156 & 0.0969 \\
\hline Intercept $(a)$ & 0.0027 & -0.0019 & -0.0003 \\
\hline Correlation coefficient (r) & 0.9992 & 0.9993 & 0.9996 \\
\hline Recovery $\% \pm \mathrm{SD}$ & $98.08 \pm 1.75$ & $98.20 \pm 1.52$ & $98.0 \pm 1.32$ \\
\hline Relative standard deviation (RSD\%) & 1.76 & 1.53 & 1.34 \\
\hline Relative error (RE\%) & 1.85 & 1.61 & 1.41 \\
\hline Limit of Detection, $\mu \mathrm{g} \mathrm{mL}{ }^{-1}$ & 0.06 & 0.14 & 0.13 \\
\hline Limit of Quantification, $\mu \mathrm{g} \mathrm{mL}^{-1}$ & 0.19 & 0.47 & 0.43 \\
\hline$t$ - value ${ }^{\mathrm{b}}$ & 1.18 & 1.44 & 1.32 \\
\hline$F$ - value ${ }^{b}$ & 2.67 & 2.02 & 1.52 \\
\hline
\end{tabular}

${ }^{a} A=a+b C$ where $c$ is the concentration in $\mu g m L^{-1}$.

${ }^{b}$ Theoretical values for $t$ and $F$-values at five degrees of freedom and $95 \%$ confidence limit $(P=0.05)$ are $(t$ $=2.571)$ and $(F=5.05)$.

\subsection{Applications}

The proposed methods were used for the determination of deltamethrin in its formulations (Table 3), water samples (tap and river) (Table 4), grains (rice and wheat) samples (Table 4) vegetables and fruit samples (Table 4).

Table3. Determination of deltamethrin pyrethriod insecticide in its formulations.

\begin{tabular}{|l|l|l|l|l|}
\hline Technical grade sample & \multicolumn{2}{|l|}{ Recovery \% $^{\text {a }}$} & Reference method [18] \\
\hline & Method A & Method B & Method C & \\
\hline DeltaGard SC (50 g/L) $^{\prime}$ & $95.90 \pm 1.10$ & $96.0 \pm 0.90$ & $97.0 \pm 1.20$ & $96.4 \pm 0.85$ \\
\hline$t$-value $^{\mathrm{b}}$ & 0.80 & 0.72 & 0.91 & \\
\hline$F$-value $^{\mathrm{b}}$ & 1.67 & 1.12 & 1.99 & \\
\hline Deltamethrin (5.0\% EC) & $97.0 \pm 0.95$ & $96.50 \pm 1.15$ & $96.8 \pm 0.90$ & $96.0 \pm 1.05$ \\
\hline$t$-value & 1.58 & 0.72 & 1.29 & \\
\hline$F$-value $^{\mathrm{b}}$ & 1.22 & 1.20 & 1.36 & \\
\hline
\end{tabular}

${ }^{\mathrm{a}}$ Mean \pm standard deviation $(n=6)$.

${ }^{b}$ Theoretical values for $t$ and $F$-values at five degrees of freedom and 95\% confidence limit $(P=0.05)$ are $(t$ $=2.571)$ and $(F=5.05)$. 
Sensitive Spectrophotometric Determination of Deltamethrin Insecticide in its Formulation and Environmental Samples

Table4. Estimation of deltamethrin in fortified water, grain, vegetables and fruits samples using the proposed methods.

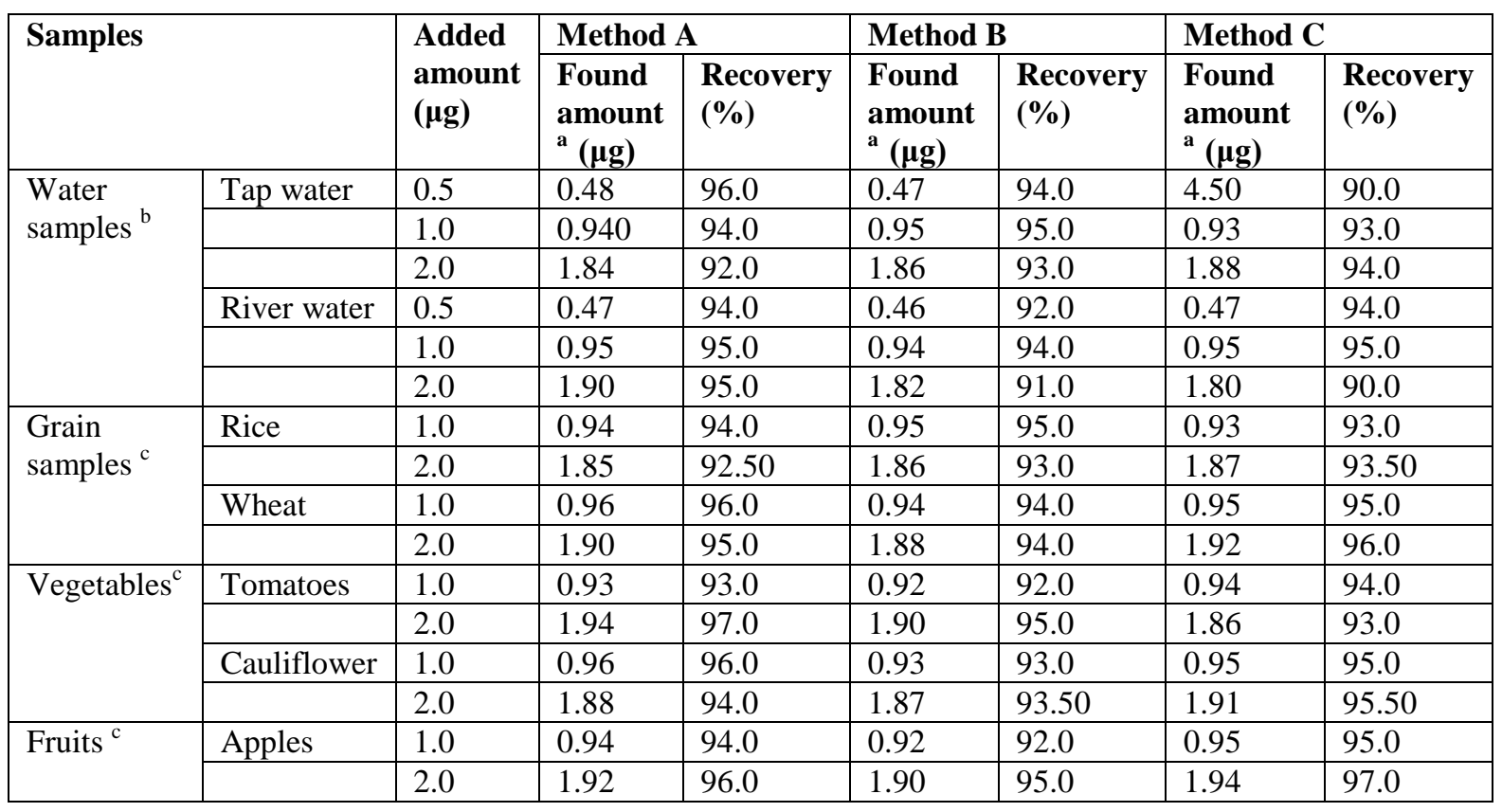

${ }^{a}$ Mean of six replicates analyses.

${ }^{b}$ Water sample $25 \mathrm{~mL}, 1.0 \mathrm{~mL}$ aliquots of sample was analyzed, after treatment as described in the procedure.

${ }^{c}$ Sample $25 \mathrm{~g}$ (sample taken from a field where deltamethrin had been sprayed).

\section{Conclusion}

The proposed methods are facile, rapid and sensitive and can be used for the determination of deltamethrin as a synthetic pyrethroid in trace amounts. Interference from many substances other than aldehydes is eliminated by the selective extraction procedure used and also by measuring the absorbance of the sample against that of a corresponding crop control (blank). Additional advantages of the these methods are that color develop instantaneously and stable for longer time. Thus, excess reagent has no effect on the absorbance of the colored derivative. Moreover, these methods do not involve the elaborate cleanup procedures required by other reported methods and can be suitably adopted for routine checkup of the purity of $\mathrm{s}$ deltamethrin in its formulations and environmental samples.

\section{REFERENCES}

[1] Narahashi T., Ginsburg K. S., Nagata K., Song J. H. and Tatebayash H., Ion channels as targets for insecticides, Neurotoxicology, 19, 581 (1998).

[2] Weston D. P., Holmes R. W., You J. and Lydy M. J., Aquatic toxicity due to residential use of pyrethroid insecticides. Environ. Sci. Technol., 39, 9778 (2005)

[3] Akre C. J. and MacNeil J. D., Determination of Eight Synthetic Pyrethroids in Bovine Fat by Gas Chromatography with Electron Capture Detection, J. AOAC Int., 89, 1425 (2006).

[4] Kumar B., Kumar S.,Prakash D., Singh S.K., Mishra M., Jain P.K., Gaur R., Goel G., Sharma C.S., Kamyotra J.S. and Gautam S.P., Determination of pyrethroid insecticides by reversed phase high performance liquid chromatography-diode array detector (HPLC-DAD) with different types of column, Proceedings of the Indian National Science Academy 77, 51 (2011).

[5] Kulikov A.U., Determination of pyrethroid insecticide deltamethrin by micellar liquid chromatography with spectrophotometric detection, Chromatographia, 66, 303(2007).

[6] Pavan F.A., Dallago R.M., Zanella R. and Martins A.F., Determination of deltamethrin in cattle dipping baths by high- performance liquid chromatography, J. Agri. Food Chem., 47, 174 (1999). 
[7] Manjunatha B., Subba Reddy G.V., Tirado J.O., Salas P.F. and Ortiz D.R., Determination of residues of deltamethrin in water and liver tissue of Zebrafish (Danio rerio) by HPLC, Der Pharma Chem., 7, 149 (2015).

[8] Boonchiangma S.,Ngeontae W. and Srijaranai S., Determination of six pyrethroid insecticides in fruit juice samples using dispersive liquid-liquid microextraction combined with high performance liquid chromatography, Talanta, 88, 209 (2012).

[9] Prodhan M.D.H., Papadakis E.-N. and Papadopoulou-Mourkidou E., Analysis of pesticide residues in melon using QuEChERS extraction and liquid chromatography triple quadrupole mass spectrometry, Int. J. Environ. Anal. Chem., (2015), Article in Press.

[10] Costa A.I.G., Queiroz M.E.L.R., Neves A.A., De Sousa F.A. and Zambolim L., Determination of pesticides in lettuce using solid-liquid extraction with low temperature partitioning, Food Chem., 181, 64 (2015).

[11] Hernandes T., Dores E.F.G.C., Ribeiro M.L.,Rossignoli P.A. and Malm O., Simple method to determine residual cypermethrin and deltamethrin in bovine milk, J. Braz. Chem. Soc., 25, 1656 (2014).

[12] López-Blanco C., Gómez-Álvarez S., Rey-Garrote M., Cancho-Grande B. and Simal-Gándara J., Determination of pesticides by solid phase extraction followed by gas chromatography with nitrogen-phosphorous detection in natural water and comparison with solvent drop microextraction, Anal. Bioanal. .Chem., 384, 1002 (2006).

[13] Samatha K. and Sreedhar N.Y., Polarographic determination of deltamethrin, Talanta, 49, 53 (1999).

[14] Ge S., Lu J., Ge L., Yan M. and Yu J., Development of a novel deltamethrin sensor based on molecularly imprinted silica nanospheres embedded CdTe quantum dots, Spectrochimica Acta A., 79, 1704 (2011).

[15] Sundari P.A. and Manisankar P., Development of nano poly(3-methyl thiophene)/multiwalled carbon nanotubes sensor for the efficient detection of some pesticides, J. Braz. Chem. Soc., 22, 746 (2011).

[16] Abirama Sundari P.L. and Manisankar P., Development of ultrasensitive surfactants doped poly(3,4- ethylenedioxythiophene)/multiwalled carbon nanotube sensor for the detection of pyrethroids and an organochlorine pesticide, J. App. Electrochem., 41(1), 29 (2011).

[17] Raju R.V., Naidu R.R., Spectrophotometric determination of decamethrin and its residues in insecticidal formulations and in water, J. AOAC Int., 77748 (1994).

[18] Suresh Kumar K., Lokanath Swaroop B., Suvardhan K., D. Rekha, Jayaraj B. and Chiranjeevi P. , Facile and Sensitive Spectrophotometric Determination of Synthetic Pyrithroids in Their Formulations, Water and Grain Samples, Environmental Monitoring and Assessment, 122, 1 (2006).

[19] Janghel E.K., Rai J.K., Rai M.K. and Gupta V.K., A new sensitive spectrophtometric determination of cypermethrin insecticide in environmental and biological samples, J. Braz. Chem. Soc., 18, 590 (2007).

[20] Vitthal B. P., Murlidhar T. S. and Sudhakar V. P., Thin-layer chromatographic detection of pyrethroid insecticides containing a nitrile group, Analyst, 117, 75 (1992).

[21] Miller J. N. and Miller J. C., "Statistics and Chemometrics for Analytical Chemistry," $5^{\text {th }}$ ed., Prentice Hall, England, (2005). 